Volume 7

Issue 4 -- Women and Cancer

Article 9

$10-23-2020$

\title{
Dancing During Labor: Are Women Down to Boogie?
}

Drew A. Horter

Kayla Heslin

Marie Forgie

Emily Malloy

Jessica J. F. Kram

Follow this and additional works at: https://aah.org/jpcrr

Part of the Alternative and Complementary Medicine Commons, Family Medicine Commons, Maternal and Child Health Commons, Maternal, Child Health and Neonatal Nursing Commons, Nursing Midwifery Commons, Obstetrics and Gynecology Commons, and the Women's Health Commons

\section{Recommended Citation}

Horter DA, Heslin K, Forgie M, Malloy E, Kram JJ. Dancing during labor: Are women down to boogie? J Patient Cent Res Rev. 2020;7:349-54. doi: 10.17294/2330-0698.1746

Published quarterly by Midwest-based health system Advocate Aurora Health and indexed in PubMed Central, the Journal of Patient-Centered Research and Reviews (JPCRR) is an open access, peer-reviewed medical journal focused on disseminating scholarly works devoted to improving patient-centered care practices, health outcomes, and the patient experience. 


\title{
Dancing During Labor: Are Women Down to Boogie?
}

\author{
Drew A. Horter, ${ }^{1,2,3}$ Kayla Heslin, MPH, , ${ }^{1,2,3}$ Marie Forgie, DO,, Emily Malloy, APNP, CNM, ${ }^{2,5}$ \\ Jessica J. F. Kram, MPH ${ }^{2,3}$ \\ ${ }^{1}$ Advocate Aurora Research Institute, Advocate Aurora Health, Milwaukee, WI; ${ }^{2}$ Aurora UW Medical Group, Advocate \\ Aurora Health, Milwaukee, Wl; ${ }^{3}$ Center for Urban Population Health, Milwaukee, WI; ${ }^{4}$ Obstetrics and Gynecology, Aurora \\ Sinai Medical Center, Milwaukee, WI; ${ }^{5}$ Midwifery and Wellness Center, Aurora Sinai Medical Center, Milwaukee, WI
}

\begin{abstract}
Recent social media trends have demonstrated increased interest in dancing during the final weeks of pregnancy and labor. However, there is limited evidence about dancing during labor and its impact on labor pain and duration as well as patient satisfaction. Before conducting a prospective study, given that enrollment is often challenging, our feasibility study aimed to assess the willingness of pregnant women to participate in a future study evaluating low-impact dance during labor. We anonymously surveyed a convenience sample of English-speaking/reading pregnant women who presented for prenatal care at 1 of 3 clinics from June 2019 to July 2019. Questions related to women's interest in dancing during labor and limited demographic information were collected and analyzed. Overall, $88.6 \%$ of pregnant women who completed the survey expressed interest in participating in a future study on low-impact dance during labor, with Caucasian patients and those $\geq 35$ years of age being less interested in future participation ( $P<0.05$ for both). Interest in participating was not influenced by any other demographic characteristic, pregnancy history, or current activity level. Given sufficient interest among pregnant women in participating in a study aimed at evaluating the potential benefits of lowimpact dance during labor, enrollment numbers may be easier to achieve than previously expected. (J Patient Cent Res Rev. 2020;7:349-354.)
\end{abstract}

Keywords pregnancy, first stage labor; dance; feasibility study

$\mathrm{W}$ omen with an uncomplicated pregnancy may benefit from exercising throughout their pregnancy. ${ }^{1}$ Aerobic dance may be one lowimpact exercise of minimal risk that pregnant women can participate in. ${ }^{1-4}$ Studies and opinion articles have described dancing during pregnancy as joyful, relaxing, strengthening, and offering a connection between the mother and her developing baby. ${ }^{5-9}$

Dancing during pregnancy has become increasingly popular from social media trends like the "Baby Momma Challenge," which challenges pregnant women to perform a dance during the last weeks of pregnancy prior to labor. ${ }^{10}$ Additionally, videos of women dancing during the first stage of labor have become increasingly popular, with media outlets posting videos of pregnant women

Corresponding author: Jessica J. F. Kram, MPH, Aurora Sinai Medical Center, 1020 N. 12th Street, \#4180, Milwaukee, WI 53233 (jessica.kram@aah.org) dancing during early latent labor. ${ }^{11}$ While there has been research on the benefits of exercise throughout pregnancy, few studies have evaluated exercise and its effect on pain and the progression of the first stage of labor. A 2013 narrative review examining the relationship between movement and the duration of the first and second stage of labor found conflicting results among studies, suggesting that further research was needed. ${ }^{12}$

Even fewer articles and studies have discussed the benefits of dancing during the first stage of labor for pain reduction, labor progression, and patient satisfaction. To our knowledge, only one unregistered randomized trial conducted in Iran identified that mean pain and patient satisfaction scores were significantly better in the dance labor group when compared to the control group. ${ }^{13}$ In this study, the dance labor group was required to stay upright for at least 30 minutes, rest their arms on their partner's shoulders, tilt their pelvis, and move their hips in a circle or rock them back and forth. ${ }^{13}$ These movements may help to facilitate progression of labor, decrease pain, and improve fetal oxygenation. ${ }^{14}$ 
Given social media trends and the lack of current evidence, we conducted a feasibility study with two main objectives. As enrollment is often challenging for prospective research, with average clinical trials able to enroll approximately $32 \%$ of approached patients, ${ }^{15}$ our primary objective was to determine pregnant women's willingness to participate in a future study that aims to evaluate low-impact dance during labor. Secondarily, our study aimed to evaluate pregnant women's perception of low-impact dance as a nonpharmacological alternative for pain management during labor.

\section{METHODS}

Following a review of the literature, ${ }^{16}$ we conducted a feasibility study using a convenience sample of Englishspeaking/reading pregnant women who presented for prenatal care at 1 of 3 clinics in a large, integrated health care system in southeastern Wisconsin from June 2019 to July 2019. Eligible women were approached during routine prenatal visits and were asked to voluntarily complete an anonymous survey. Prior to completing the survey, women were asked to complete a prescreening survey and were further excluded if they did not want to participate, had been previously approached, or were not comfortable reading/speaking English. Regardless of participation, women were offered a small treat (eg, granola bar). The study was approved by the local institutional review board as exempt research.

All surveys were administered via an iPad through nPhase's REDCap Cloud, a secure electronic data capture application used for study-specific data collection. The survey included up to 23 questions regarding demographics, pregnancy information, and women's opinions about nonpharmacological methods for pain during labor either in addition to or in place of medications for pain relief, as well as assessment of interest in future participation in a larger study. The survey was adaptive, and each question was based on the response to the previous question. The majority of questions were in multiple-choice format, and therefore, variables were typically categorical. All data collected were anonymously and entirely self-reported by the participant. A study co-investigator was present to assist participants when questions arose regarding the survey.

Descriptive statistics were used to describe interest in participating in a future study. Interest or willingness to use nonpharmacological methods either in addition to or in place of medications for pain relief at time of delivery were also described. Differences in characteristics between those willing or not willing to participate in a future study were compared using Fisher's exact test. Significance was associated with a P-value less than 0.05 . All data were analyzed using SAS 9.4 software (SAS Institute Inc.).

\section{RESULTS}

In total, 177 pregnant women were approached to participate; 33 women declined to participate and $12 \mathrm{did}$ not meet eligibility requirements. Of the 132 surveys completed (74.6\% completion rate), only 58 (43.9\%) participants had heard of dancing during labor. However, the majority of pregnant women $(72.0 \%)$ felt that lowimpact dancing during labor may be helpful (Table 1).

Overall, $117(88.6 \%)$ pregnant women answered yes to the question "Would you participate in a research study that may have you do low-impact dancing during the beginning of labor (either in addition to or in place of medicine)?" Caucasian patients $(\mathrm{P}=0.01)$ as well as patients $\geq 35$ years of age $(\mathrm{P}=0.04)$ were less likely to be interested in future study participation (Table 2). Regardless of any other patient demographic or characteristic, such as current activity level and

Table 1. What Do You Think About Low-Impact Dancing During Labor To Help With Pain?

\begin{tabular}{lc}
\hline Answer (respondents could select more than one) & $\mathbf{N = 1 3 2 ( 1 0 0 \% )}$ \\
\hline I think it may be helpful & $95(72.0 \%)$ \\
I do not think it may be helpful & $5(3.8 \%)$ \\
I think it would make things worse & $2(1.5 \%)$ \\
I think it would make things better & $26(19.7 \%)$ \\
I think it would be fun & $46(34.8 \%)$ \\
I think it would take my mind off of things & $42(31.8 \%)$ \\
I think it would be hard to dance & $16(12.1 \%)$ \\
I think my pregnancy is too high risk to do this & $3(2.3 \%)$ \\
I am not sure & $14(10.6 \%)$ \\
\hline
\end{tabular}


Table 2. Patient Demographic, Pregnancy, and Health Characteristics

\begin{tabular}{|c|c|c|c|c|}
\hline \multirow[b]{2}{*}{ Variable } & \multicolumn{3}{|c|}{ Future study interest ${ }^{a}$} & \multirow[b]{2}{*}{$P$} \\
\hline & $\begin{array}{l}\text { Overall } \\
(\mathrm{N}=132)\end{array}$ & $\begin{array}{c}\text { Yes } \\
(n=117)\end{array}$ & $\begin{array}{c}\text { No } \\
(n=15)\end{array}$ & \\
\hline \multicolumn{5}{|l|}{$\operatorname{Age}^{b}$} \\
\hline$\leq 17$ years old & $6(4.6)$ & $6(5.1)$ & $0(0.0)$ & \\
\hline 18-24 years old & $45(34.1)$ & $42(35.9)$ & $3(20.0)$ & 0.04 \\
\hline 25-34 years old & $73(55.3)$ & $64(54.7)$ & $9(60.0)$ & \\
\hline$\geq 35$ years old & $8(6.1)$ & $5(4.3)$ & $3(20.0)$ & \\
\hline \multicolumn{5}{|l|}{ Racial/Ethnic } \\
\hline African American & $86(65.2)$ & $80(68.4)$ & $6(40.0)$ & 0.01 \\
\hline Caucasian & $24(18.2)$ & $17(14.5)$ & $7(46.7)$ & \\
\hline Other & $22(16.7)$ & $20(17.1)$ & $2(13.3)$ & \\
\hline \multicolumn{5}{|l|}{ BMI } \\
\hline Underweight (BMI: <18.5kg/m²) & $1(0.8)$ & $0(0.0)$ & $1(6.7)$ & -- \\
\hline Normal weight (BMI: 18.5-24.9 kg/m²) & $65(49.2)$ & $57(48.7)$ & 8 (53.3) & \\
\hline Overweight (BMI: 25.0-29.9 kg/m²) & $38(28.8)$ & $35(29.9)$ & $3(20.0)$ & \\
\hline Obese (BMl: $\geq 30$ kg/m²) & $11(8.3)$ & $10(8.5)$ & $1(6.7)$ & \\
\hline Unsure & $15(11.4)$ & $14(12.0)$ & $1(6.7)$ & \\
\hline Did not wish to share & $2(1.5)$ & $1(0.9)$ & $1(6.7)$ & \\
\hline \multicolumn{5}{|l|}{ BMI } \\
\hline Normal weight (BMI: 18.5-24.9 kg) & $65(49.2)$ & $57(48.7)$ & 8 (53.3) & 0.55 \\
\hline Overweight/Obese (BMI: $\geq 25$ kg/m²) & $49(37.1)$ & $45(38.5)$ & $4(26.7)$ & \\
\hline \multicolumn{5}{|l|}{ Location of visit } \\
\hline Midwife clinic & $93(70.5)$ & $83(70.9)$ & $10(66.7)$ & 0.70 \\
\hline Women's health clinic & $7(5.3)$ & $6(5.1)$ & $1(6.7)$ & \\
\hline Residency clinic & $32(24.2)$ & $28(24.0)$ & $4(26.6)$ & \\
\hline \multicolumn{5}{|l|}{ Number of previous deliveries } \\
\hline 0 & $47(35.6)$ & $44(37.6)$ & $3(20.0)$ & 0.43 \\
\hline 1 or 2 & $57(43.2)$ & $48(41.0)$ & $9(60.0)$ & \\
\hline 3 or more & $28(21.3)$ & $25(21.4)$ & $3(20.0)$ & \\
\hline Previous cesarean & $19(14.4)$ & $16(13.7)$ & $3(20.0)$ & 0.73 \\
\hline Previous vaginal delivery & $71(53.8)$ & $61(52.1)$ & $10(66.7)$ & 0.99 \\
\hline \multicolumn{5}{|l|}{ Current trimester } \\
\hline First & $9(6.8)$ & $8(6.8)$ & $1(6.7)$ & 0.91 \\
\hline Second & $48(36.4)$ & $42(35.9)$ & $6(40.0)$ & \\
\hline Third & $75(56.8)$ & $67(57.3)$ & $8(53.3)$ & \\
\hline \multicolumn{5}{|l|}{ Current level of activity in daily life } \\
\hline Sedentary (little to no regular exercise) & $18(13.6)$ & $15(12.8)$ & $3(20.0)$ & 0.28 \\
\hline Mildly active (30 minutes exercise, $1-3$ times weekly) & $54(40.9)$ & $51(43.6)$ & $3(20.0)$ & \\
\hline Moderately active (30-60 minutes exercise, 3-4 times weekly) & $37(28.0)$ & $31(26.5)$ & $6(40.0)$ & \\
\hline Very active (30-60 minutes exercise, $5-7$ times weekly) & $23(17.4)$ & $20(17.1)$ & $3(20.0)$ & \\
\hline Activity level changed since pregnancy & $88(66.7)$ & $81(69.2)$ & $7(46.7)$ & 0.09 \\
\hline
\end{tabular}

a Values are presented as $n(\%)$.

${ }^{b}$ Patients $\leq 17$ years of age were not included in Fisher's exact test; only 3 age groups were included.

$B M I$, body mass index. 


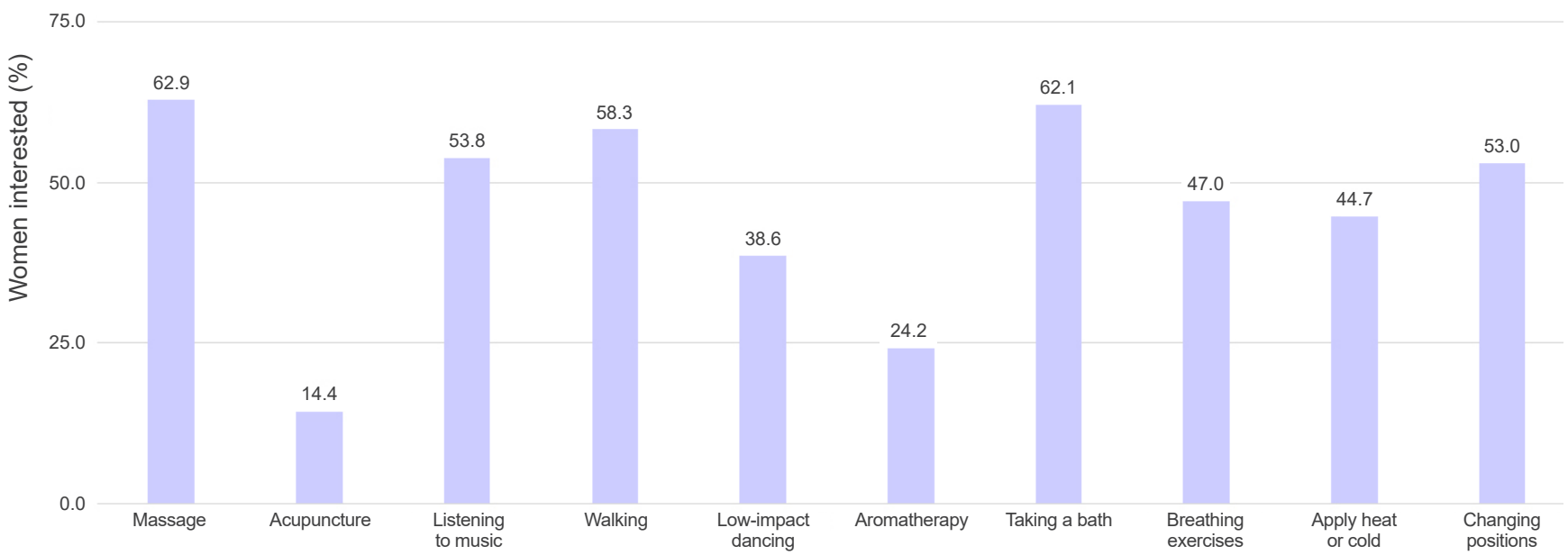

Figure 1. Interest in nonpharmacological alternatives for pain reduction. Graph shows the percentage of patients who would potentially be interested in a specific nonpharmacological alternative for pain reduction during labor, either in addition to or in place of medicine.

pregnancy history, most indicated that they would be interested in participating in a future study involving lowimpact dance during the first stage of labor (Table 2).

Reasons given by the 15 women who answered no regarding participation in a future study included health problems $(\mathrm{n}=2,13.3 \%)$, the desire to focus on birthing experience $(\mathrm{n}=6,40 \%)$, unknown expectations $(\mathrm{n}=5$, $33.3 \%)$, and other reasons ( $\mathrm{n}=2,13.3 \%)$. Of those willing to participate in a future study, $47.9 \%(\mathrm{n}=56)$ preferred dance moves and $34.2 \%(\mathrm{n}=40)$ preferred music were provided. Overall, more than $70 \%$ wanted either a video clip or photo of themselves dancing.

When asked "Would you ever use drug-free methods (ie, more natural methods) for pain relief during labor (either in addition to or in place of medicine)?", 78.0\% of participants said that they would be interested in alternative options for pain relief in addition to or in place of medicine. While there was interest in all types of nonpharmacological alternatives for pain reduction (Figure 1), only changing positions and low-impact dancing were relevant to this feasibility study. Overall, $53.0 \%$ and $38.6 \%$ of participants chose changing positions and low-impact dancing, respectively (Figure 1). Collectively, $61.4 \%$ said that they would use either.

\section{DISCUSSION}

The goal of this feasibility study was to gauge pregnant women's willingness to participate in a future prospective trial that would aim to evaluate low-impact dance during labor. In order to carry out a prospective study of this nature, it is important that the biggest obstacle, enrollment, could be overcome. Overall, $88.6 \%$ of pregnant women who completed the survey indicated that they would participate in a future study, with $61.4 \%$ of patients indicating they were interested in changing positions or low-impact dancing for pain reduction. Our rate of interest in enrollment was unexpectedly high, and while it would be advantageous to obtain such a high rate of enrollment for a prospective study, there are multiple factors that may impact or influence patient enrollment going forward.

Recruitment and enrollment are often a challenge in clinical research. However, randomized trials are necessary for improving care among pregnant women during pregnancy, in labor, and postpartum. ${ }^{17,18}$ While our feasibility study identified a high rate of interest, participants were agreeing to a hypothetical study several weeks prior to labor onset. Once in labor, patients may wish to withdraw themselves from the study or be less willing to participate. ${ }^{15}$ Moreover, due to the unpredictability of labor, investigators may withdraw participants for a variety of reasons. Therefore, it is important to ensure that sites selected for clinical research are able to recruit and enroll an adequate number of patients for a particular study. ${ }^{15,17}$ Again, based on our feasibility study, it seems that a prospective study would be able to achieve enrollment goals, despite the average patient participation rate in clinical research being $32 \% .{ }^{15}$ 
A person's decision to participate in clinical research or a randomized trial also may be impacted by study design. ${ }^{19,20}$ Our feasibility study asked pregnant women about music and dance preferences in order to better tailor future study design. Most participants indicated that they would like to listen to their own music and incorporate their own dance moves. However, some standardization of dancing duration, associated movements, and possibly music types will be necessary to limit confounding variables, standardize the intervention, and allow for generalizability of the results, which may influence study participation. Additionally, our feasibility study did not ask if pregnant women would be interested in participating in a randomized trial. Randomization is often perceived negatively or with uncertainty among patients and may further influence enrollment. ${ }^{20}$ Should a future study incorporate randomization, explanations on the study design should be provided. ${ }^{20}$

In addition to participant recruitment and enrollment challenges for prospective research, physiological and ethical complexities of clinical trials among pregnant women may impact who is eligible to participate. ${ }^{18}$ As our survey posed no risk to pregnant women, even women with high-risk or difficult pregnancies could participate. For a future study, exclusion requirements would need to be expanded and would ultimately further impact enrollment numbers. While restricting who participates in a study may impact its feasibility and generalizability, ${ }^{18}$ future research aimed at providing pregnant patients with alternative pain management options during labor is warranted. Many participants indicated interest in several nonpharmacological alternatives for pain reduction, either in addition to or place of medication, including low-impact dance and changing positions during labor.

This study had several limitations, one being that we limited the survey to English-speaking patients only. Additionally, some of the survey questions may have been difficult for women to answer (eg, women were unsure of their body mass index due to weight increases during pregnancy). Additionally, women may have been more inclined to answer "Yes" to "Would you participate in a research study that may have you do low-impact dancing during the beginning of labor (either in addition to or in place of medicine)?" because they would not have had to fill out a comment box disclosing their reasons for declining to participate. Strengths of this study included a large sample size and survey completion rate as well as inclusion of a racially diverse patient population.

The results of our survey indicate that there is significant interest in low-impact dance during labor as a nonpharmacological option for pain management. Although there will inevitably be challenges to conducting a sufficiently large, prospective, randomized trial, women responded favorably to participating in future research, therefore, enrollment may be more feasible than previously anticipated. Our findings have the potential to inform a prospective study on lowimpact dance for pain management during labor. Such a study is warranted in order to strengthen evidence for low-intervention, low-technology, nonpharmacological health care appropriate for at-low-risk women.

\section{Patient-Friendly Recap}

-While dancing during early labor may have benefits, there is limited evidence regarding its impact on labor pain and duration or on patient satisfaction.

- Of pregnant women surveyed, $88.6 \%$ expressed interest in participating in a future study on low-impact dance during labor, with African American and younger women significantly more interested in participation.

- As there was sufficient interest among pregnant women to participate in research even after going into labor, enrolling the numbers needed to conduct a randomized trial may be easier than previously expected.

\section{Acknowledgments}

We would like to thank all of the staff members at the participating clinics for assisting our research in the data collection process. Additionally, we would like to thank Caroline Toberna for coauthoring the topic synopsis ${ }^{16}$ that helped us to carry out this feasibility study.

\section{Author Contributions}

Study design: Heslin, Forgie, Malloy, Kram. Data acquisition or analysis: all authors. Manuscript drafting: all authors. Critical revision: all authors.

\section{Conflicts of Interest}

None.

\section{References}

1. American College of Obstetricians and Gynecologists. ACOG Committee Opinion No. 650: Physical activity and exercise during pregnancy and the postpartum period. Obstet Gynecol. 2015;126:e135-42. Crossref

2. McMurray RG, Katz VL, Poe MP, Hackney AC. Maternal and fetal responses to low-impact aerobic dance. Am J Perinatol. 1995;12:282-5. Crossref

3. McMurray RG, Hackney AC, Guion WK, Katz VL. Metabolic and hormonal responses to low-impact aerobic dance during pregnancy. Med Sci Sports Exerc. 1996;28:41-6. Crossref

4. Halvorsen S, Haakstad LA, Edvardsen E, Bø K. Effect of aerobic dance of cardiorespiratory fitness in pregnant women: a randomised controlled trial. Physiotherapy. 2013;99:42-8. $\underline{\text { Crossref }}$

5. Sanders SG. Dancing through pregnancy: activity guidelines for professional and recreational dancers. J Dance Med Sci. 2008;12:17-22. 
6. Henley-Einion A. The ecstasy of the sprit: five rhythms for healing. Pract Midwife. 2007;10:20, 22-3.

7. Campbell L. Movement and dance: deep medicine for pregnancy, labour and birth. Essentially MIDIRS. 2013;4(4):40-5.

8. Jackson I. Empowering embodiment through belly dancing in pregnancy: a phenomenological exploration. Pract Midwife. 2015;18:27-30.

9. MacGregor HE. The belly dances, the muscles follow. Los Angeles Times. Published November 18, 2002; accessed March 7, 2019. http://articles.latimes.com/2002/nov/18/health/he-fitness 18

10. Michallon C. Getting in the family grove! Woman who is pregnant with triplets tries to dance her way into labor, shaking her enormous baby bump while boogying with her husband and their daughter. DailyMail.com. Published October 22, 2018; accessed June 7, 2019. https://www.dailymail.co.uk/ femail/article-6303595/Heavilypregnant-woman-expectingTRIPLETS-tries-dance-waylabor.html

11. Baulkman J. Doctor helps women through labor by dancing with them in hilarious videos - and research shows it does help. DailyMail.com. Published January 19, 2018; accessed June 7, 2019. https://www.dailymail.co.uk/health/article-5289287/ Doctor-helps-womenlabor-dancing-them.html

12. Hollins Martin CJ, Martin CR. A narrative review of maternal physical activity during labour and its effects upon length of first stage. Complement Ther Clin Pract. 2013;19:44-9. Crossref

13. Abdolahian S, Ghavi F, Abdollahifard S, Sheikhan F. Effect of dance labor on the management of active phase labor pain \& clients' satisfaction: a randomized controlled trial study. Glob J Health Sci. 2014;6:219-26. Crossref
14. Moore C. Belly dance \& birth. Midwifery Today Int Midwife. 2005;(73):28-9.

15. Harter G, Darden J, McMenemy N, McElvy T, Hendrich A. Consent and enrollment process: achieving high enrollment rates for obstetric research. Appl Nurs Res. 2016;29:101-6. $\underline{\text { Crossref }}$

16. Toberna CP, Horter D, Heslin K, Forgie MM, Malloy E, Kram JJF. Dancing during labor: social media trend or future practice? J Patient Cent Res Rev. 2020;7:213-7. Crossref

17. Foulkes MA, Grady C, Spong CY, Bates A, Clayton JA. Clinical research enrolling pregnant women: a workshop summary. J Womens Health (Larchmt). 2011;20:1429-32. Crossref

18. Kaye DK. The moral imperative to approve pregnant women's participation in randomized clinical trials for pregnancy and newborn complications. Philos Ethics Humanit Med. 2019;14(1):11. Crossref

19. Den Hollander GC, Browne JL, Arhinful D, van der Graff R, Klipstein-Grobusch K. Power difference and risk perception: mapping vulnerability within the decision process of pregnant women towards clinical trial participation in an urban middleincome setting. Dev World Bioeth. 2018;18:68-75. Crossref

20. Oude Rengerink K, Logtenber S, Hooft L, Bossuyt PM, Mol BW. Pregnant womens' concerns when invited to a randomized trial: a qualitative case control study. BMC Pregnancy Childbirth. 2015;15:207. Crossref

(C) 2020 Advocate Aurora Health, Inc. 